\title{
The effects of selective breeding against scrapie susceptibility on the genetic variability of the Latxa Black-Faced sheep breed
}

\author{
Leopoldo Alfonso $^{\mathrm{a} *}$, Analia PARAdA ${ }^{\mathrm{a}}$, Andrés LegARRA ${ }^{\mathrm{b} * *}$, \\ Eva UGARTE ${ }^{\mathrm{b}}$, Ana ARANA ${ }^{\mathrm{a}}$ \\ a Departamento de Producción Agraria, Universidad Pública de Navarra, \\ 31006 Pamplona, Spain \\ ${ }^{\mathrm{b}}$ NEIKER, A.B., 01080 Vitoria-Gasteiz, Spain
}

(Received 9 November 2005; accepted 21 March 2006)

\begin{abstract}
Breeding sheep populations for scrapie resistance could result in a loss of genetic variability. In this study, the effect on genetic variability of selection for increasing the $A R R$ allele frequency was estimated in the Latxa breed. Two sources of information were used, pedigree and genetic polymorphisms (fifteen microsatellites). The results based on the genealogical information were conditioned by a low pedigree completeness level that revealed the interest of also using the information provided by the molecular markers. The overall results suggest that no great negative effect on genetic variability can be expected in the short time in the population analysed by selection of only $A R R / A R R$ males. The estimated average relationship of $A R R / A R R$ males with reproductive females was similar to that of all available males whatever its genotype: $0.010 v$ s. 0.012 for a genealogical relationship and $0.257 v s .0 .296$ for molecular coancestry, respectively. However, selection of only ARR/ARR males implied important losses in founder animals ( 87 percent) and low frequency alleles ( 30 percent) in the ram population. The evaluation of mild selection strategies against scrapie susceptibility based on the use of some $A R R$ heterozygous males was difficult because the genetic relationships estimated among animals differed when pedigree or molecular information was used, and the use of more molecular markers should be evaluated.
\end{abstract}

genetic variability / scrapie / Manech / Latxa / sheep

\footnotetext{
*Corresponding author: leo.alfonso@ unavarra.es

** Present address: Station d'amélioration génétique des animaux, INRA, 31326 CastanetTolosan, France
} 


\section{INTRODUCTION}

Genetic control programmes of scrapie susceptibility are now underway in several countries founded on the strong association of scrapie with the prion protein $(\operatorname{Pr} P)$ genotype. Current research indicates that there is evidence to show that certain genotypes may be resistant to scrapie infection or at least may reduce the transmission of this insidious neurological disease of sheep [9].

Although some atypical scrapie cases have been found in homozygous $A R R$ genotypes $($ e.g. $[7,25])$, in the European Union, the breeding programmes are still aimed at increasing the frequency of the $A R R$ allele while reducing the prevalence of those alleles (especially the $V R Q$ ) which have been shown to contribute to susceptibility to scrapie [11]. $\operatorname{Pr} P$ alleles are defined by reference to the amino acids encoded by codons 136, 154 and 171 of the gene.

The selection of animals for increasing the ARR allele frequency could result in a loss of genetic variability and a reduction in the effective size of sheep populations implying that genetic drift will increase, as well as inbreeding. These consequences are especially dangerous in breeds facing extinction, and important in populations undergoing selection because of the loss of the heritable part of the genetic variance. The selection against scrapie susceptible alleles could negatively affect, to some degree, the genetic efforts carried out in populations undergoing selection, and the management efforts carried out in populations with the endangered status of conservation. For example, in the United Kingdom, the National Scrapie Plan (NSP) is considered by some authors [6] to be responsible for a loss of irretrievable genetic resources and a long-term impact on the genetic and hence phenotypic qualities of the national flock. Consequently, it is of interest to evaluate the magnitude of this effect to take it into account to design the selection strategy.

The analysis of genetic variability can be done using different criteria [30] that do not offer the same information on genetic variability albeit all of them are useful to estimate the loss of genetic variability conditional on the available information.

The information available on pedigree information (especially the identity of the sire) is often unknown in sheep populations due to their extensive production system characterised by the use of pastures by flocks with a large number of ewes and several rams and little use of artificial insemination [19]. The development of molecular markers led to consider the molecular diversity estimation as a possible and even recommended alternative, in order to establish the depletion of genetic variability when there is an important lack of pedigree information [34]. 
Table I. Description of pedigree information available from Latxa Black-Faced type Navarra.

\begin{tabular}{cc}
\hline Total number of animals & 54623 \\
number of males & 2133 \\
number of females & 52490 \\
Animals with both parents unknown & \\
\% of animals with unknown parents & 46 \\
$\begin{array}{c}\text { Animals with both parents known } \\
\text { \% of animals with both parents known }\end{array}$ & 26 \\
$\begin{array}{c}\text { \% of animals born } \\
\text { before 1984 }\end{array}$ & 6 \\
& $\begin{array}{c}\text { between 1984-1993 } \\
\text { between 1994-2003 }\end{array}$ \\
\hline
\end{tabular}

This work was aimed at discussing the loss of genetic variability caused by selection for increasing the $A R R$ allele frequency in the Latxa breed, a dairy sheep selected for milk production during the last twenty years. Estimates of genetic variability were obtained using pedigree and genetic polymorphism information and later compared.

\section{MATERIALS AND METHODS}

\subsection{Breed and pedigree information}

The Latxa is a local dairy sheep breed from the north of Spain, also present in the southwest of France (the name given is Manech). Within this breed different types have been described, Latxa Blond-Faced, and Basque and Navarra Latxa Black-Faced [14].

The Latxa Black-Faced type Navarra was chosen in this study because of the larger pedigree information recorded in comparison to the other types and other breeds also available for the study. The Navarra type has its own breeding programme, started in 1984. Albeit not completely, it can be considered a closed population of about 130000 ewes, being around 20 percent in official milk recording [35].

A dataset containing pedigree information on 54623 animals Latxa BlackFaced type Navarra, distributed since 1984 in a total of 123 farms, was provided by CONFELAC (Latxa breeders associations' confederation). Pedigree information is summarised in Table I. 


\section{2. $\operatorname{PrP}$ polymorphism information}

The frequencies of $\operatorname{Pr} P$ alleles have been previously estimated in Latxa Black-Faced type Navarra by Legarra et al. [22] as 0.670 for $A R Q, 0.212$ for $A R R, 0.083$ for $A R H, 0.032$ for $V R Q$ and 0.003 for $A H Q$ alleles.

All the males in use or to be tested in the selection scheme in 2002 were previously genotyped for $\operatorname{Pr} P$ gene and a blood sample kept by the breeders association (ASLANA, Latxa Navarra breeders association). The $\operatorname{Pr} P$ genotypes were determined by Spanish Central and Regional Administration by usual DNA extraction, PCR amplification and purification, codon polymorphism determination by Multiplex Kit and capillary DNA sequencer [24].

From the 404 males genotyped for $\operatorname{PrP}$ by ASLANA till the end of 2004, 96 were males born in the year 2002 with information on both parents, and they were considered in this study as future reproductive males to be introduced in the breeding scheme. The $\operatorname{PrP}$ genotype distribution of these 96 males analysed was the following: $44 A R Q / A R Q, 36 A R R / A R Q$, $13 A R R / A R R, 2 A R Q / A R H$, and $1 A R R / A R H$. The corresponding allele frequencies ( 0.33 for $A R R, 0.66$ for $A R Q$ and 0.01 for $A R H)$ were similar to that previously estimated in the population and above mentioned [22].

\subsection{Genetic polymorphism analysis}

Microsatellite genotypes were determined at each of 15 loci for the sample of 96 young males considered. The microsatellites were the following: CSRD0247, INRA0023, INRA0049, INRA0063, MAF0065, MAF0214, MCM0042, MCM0527, OARAE0119, OARAE0129, OARCP0049, OARFCB0020, OARFCB0304 and OLADRB2 isolated from domestic sheep (additional information on markers can be found at SheepBase http://www.thearkdb.org/) and one locus (D5S2) isolated from cattle [33]. These markers were used because they were combined into two PCR multiplexes, developed and tested by Rendo et al. [28] from the markers recommended by the ISAG. Therefore, their use was simple and reliable. The DNA extraction, the polymerase chain reaction (PCR) amplification, the PCR products detection and the final analyses were performed as described by Rendo et al. [29]. Microsatellite information is summarised in Table II. 
Table II. Description of genetic polymorphism information from Latxa Black-Faced type Navarra.

\begin{tabular}{lcccc}
\hline Marker & Chromosome & $\begin{array}{c}\text { No. of } \\
\text { alleles }\end{array}$ & $\begin{array}{c}\text { Expected } \\
\text { heterozygosity }\end{array}$ & $\begin{array}{c}\text { Polymorphic } \\
\text { informative content }\end{array}$ \\
\hline CSRD0247 & 14 & 10 & 0.76 & 0.58 \\
D5S2 & - & 6 & 0.53 & 0.48 \\
INRA0023 & 1 & 13 & 0.85 & 0.73 \\
INRA0049 & 1 & 10 & 0.81 & 0.72 \\
INRA0063 & 14 & 9 & 0.66 & 0.54 \\
MAF0065 & 15 & 6 & 0.77 & 0.63 \\
MAF0214 & 16 & 4 & 0.43 & 0.30 \\
MCM0042 & 9 & 8 & 0.70 & 0.54 \\
MCM0527 & 5 & 8 & 0.74 & 0.55 \\
OARAE0119 & 19 & 7 & 0.71 & 0.54 \\
OARAE0129 & 5 & 3 & 0.51 & 0.21 \\
OARCP0049 & 17 & 12 & 0.82 & 0.65 \\
OARFCB0020 & 2 & 10 & 0.81 & 0.64 \\
OARFCB0304 & 19 & 7 & 0.83 & 0.68 \\
OLADRB2 & 20 & 9 & 0.82 & 0.70 \\
\hline Average & & 8.1 & 0.72 & 0.57 \\
\hline
\end{tabular}

\subsection{Estimation of genetic variability}

The genetic variability within the set of 96 rams with pedigree and genetic polymorphism information was estimated and compared with the variability estimated within the subset of the 13 rams with the $\operatorname{Pr} P$ genotype $A R R / A R R$.

\subsubsection{Pedigree information}

The genetic variability was estimated from pedigree information using ENDOG v3.0 [16] and PEDIG [4] software. The statistics considered were the following:

(1) Number of ancestors, effective number of ancestors (computed using ENDOG [16] as $f_{a}=1 / \sum_{k=1}^{n} p_{k}^{2}$ where $p_{k}$ is the marginal contribution of ancestor $k$ ) and number of ancestors explaining 50 percent of the genetic variability.

(2) Expected marginal contribution of the ancestors contributing the most in the whole population, computed according to Boichard [5] methodology used by ENDOG [16] as $p_{k}=q_{k}\left(1-\sum_{i=1}^{n-1} a_{i}\right)$ where $q_{k}$ is the expected genetic contribution of the ancestor $k$, and $a_{i}$ is the expected genetic contributions of the $(n-1)$ selected ancestors to individual $k$. 
(3) Average coefficient of relationship $(A R)$ within and between reference populations, defined as the probability that an allele randomly chosen from the whole population in the pedigree belonged to a given animal and computed by the programme par2.f included in PEDIG [4].

These statistics were computed for both populations considered (the 96 rams with known $\operatorname{Pr} P$ genotype born in 2002, and the 13 rams with $\operatorname{Pr} P$ genotype $A R R / A R R$ born in 2002) and two additional reference populations constituted by (1) males and (2) females with both parents known and born from 1998 to 2002.

\subsubsection{Genetic polymorphism information}

Similarly, using the genetic polymorphism information, the genetic variability was estimated using MOLKIN v2.0 software [17] considering the following statistics:

(1) Average molecular coancestry, obtained by averaging the molecular coancestry values for all the pairs of individuals computed as $f_{i j}=$ $\sum_{l=1}^{L} 1 / 4\left[I_{11}+I_{12}+I_{21}+I_{22}\right]$

$\frac{\sum_{l=1}\left(/ 4 I_{11}+I_{12}+I_{21}+I_{22}\right.}{L}$ being $I_{x y}=1$ when allele $x$ on locus $l$ in individual $i$ and allele $y$ in the same locus in individual $j$ are identical, and zero otherwise.

(2) Within- and between-subpopulation kinship distance, obtained by averaging the kinship values for all the within- or between-population pairs of individuals $(i, j)$ computed as $D_{i j}=\left[\left(s_{i}+s_{j}\right) / 2\right]-f_{i j}$ being $s_{i(j)}$ the self-coancestry coefficient of individual $i(j)$ computed as $s_{i(j)}=\frac{\sum_{l=1}^{L} I}{L}$ being $I=1$ when individual $i(j)$ is homozygous on locus $l$ and 0.5 otherwise.

(3) Wright $F$-statistics $F_{I S}$ and $F_{S T}$ defined, respectively, as heterozygote deficiency within population and between populations, and obtained as $F_{I S}=$ $\frac{\tilde{F}-\tilde{f}}{1-\tilde{f}}$ and $F_{S T}=\frac{\tilde{f}-\bar{f}}{1-\tilde{f}}$ where $\tilde{f}, \tilde{F}$, are respectively, the mean coancestry and the inbreeding coefficient of subpopulations averaged for the whole population, and $\bar{f}$ is the average coancestry over the entire population.

These statistics were computed for the population of all the 96 rams with known $\operatorname{PrP}$ genotype born in 2002, and the 13 rams with $\operatorname{PrP}$ genotype $A R R / A R R$ born in 2002.

\subsection{Evaluation of a mild selection regime}

The use of $A R R$ heterozygous males free of the $V R Q$ allele $(A R R / x x x)$ to be mated with $A R R$ carrier females is an alternative to be evaluated in order to 
mitigate the loss of genetic variability, as opposed to the exclusive use of homozygous males. Nowadays, the legislation allows the Breeders Associations to establish different alternatives in the selection against scrapie genetic susceptibility. An arbitrary mild selection regime was here assumed consisting of the use without preference of homozygous and heterozygous rams under the restriction that more than 80 percent of males were $A R R / A R R$; i.e. it was considered that three of the $37 A R R / x x x$ available males could be used indifferently along with the $13 A R R / A R R$ rams.

The criterion to select these three males should be the minimisation of the average coancestry among the reproductive individuals weighted by their contributions to the next generation [8]. Actually, this criterion is difficult to apply because the contributions to the next generation cannot be programmed in Latxa Black-Faced since they will depend on genetic value, artificial insemination aptitude, semen availability, and other testing criteria of the breeding programme.

Alternatively, the criterion considered was the selection of the three $A R R / x x x$ males with the lower average coancestry coefficient with the other rams considered as reproductive males (13 ARR/ARR and 37 ARR/ $x x x$ males). Pedigree and molecular information were alternatively considered in the computation of the average coancestry coefficients to compare both sources of information.

\section{RESULTS}

\subsection{Pedigree parameters}

The pedigree completeness level was small in the population analysed. Only 26 percent of animals in genealogical data set have both parents known whereas 46 percent of the animals have both parents unknown (Tab. I). This situation and the fact that 61 percent of animals were born in the last decade indicate that genetic variability results obtained from pedigree analysis could be insufficient and they should be carefully interpreted. With a similar pedigree completeness level Huby et al. [19] excluded one of the breeds from the analysis (Blanc du Massif Central with a 25 percent of animals with both parents known). Here, however, the pedigree analysis was carried out because the Latxa Black-Faced type Navarra is one of the north-Spanish local or foreign populations with a higher pedigree completeness level and therefore the best available reference to evaluate the loss of genetic variability in north Spanish dairy sheep. For example, the percentage of animals with both parents known in Latxa Blond-Faced or Carranzana is around 20 and 8 percent respectively. 


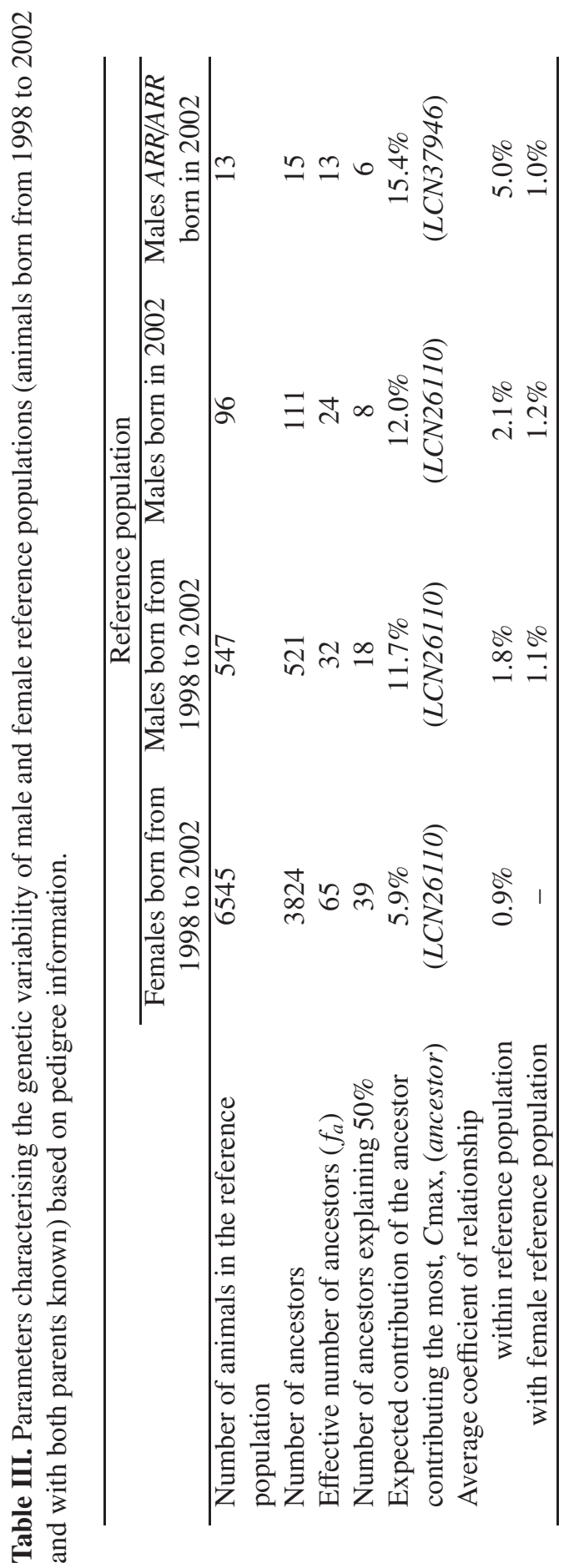


The results from available information indicate that the use of $A R R / A R R$ males exclusively will relevantly reduce the genetic variability of males (Tab. III). Comparing the scenario of using all the males born in 2002 with the scenario of using only the $A R R / A R R$ males born the same year, the effective number of ancestors is reduced to 46 percent and the average coefficient of relationship between males is increased from 2.1 to 5.0 percent. However, when comparing the average coefficient of relationship between the different reference populations of males and the population of females born from 1998 and 2002, the effect of the selection of $A R R / A R R$ males seems to be negligible. This effect can be interpreted looking at the ancestor contributing the most in the different reference populations. The male contributing the most in males and females born from 1998 to 2002 is the same (LCN26110), as it is in the population of males born in 2002 . However, this male is not the one contributing the most in the population of males ARR/ARR born in 2002 (it is another male not included in Table IV with an expected contribution of 15.4 percent), and neither in the whole population (LCN00158, Tab. IV).

Table IV summarises the 10 ancestors contributing most to the Latxa BlackFaced type Navarra breed according to the genealogical information available. All these 10 ancestors are male and are represented in the populations of females and males born from 1998 to 2002. Only one male (LCN24622) is not represented in the population of males born in 2002 and only one male ( LCN26110) is represented in the population of $A R R / A R R$ males born in 2002.

\subsection{Genetic polymorphism parameters}

The degree of information contained in the fifteen microsatellite markers analysed was high in most of them with the exception of markers OARAE0129 and MAF0214 (Tab. II) even though they are recommended for parentage verification [20] and sheep diversity measurement [13] and are highly variable in other sheep populations $[2,10,21,32]$. The resulting average number of alleles, expected heterozygosity and polymorphic information content were similar or higher than values obtained when characterising the genetic variability in other breeds and with other microsatellite panels [1-3, 10,21, 27, 29].

The results from the information offered by the 15 microsatellites analysed also indicate, like in the pedigree analysis, that the use of only ARR/ARR males will reduce the genetic variability of males (Tab. V). The mean average molecular coancestry is incremented by 15 percent and the kinship distance within population reduced by 11 percent. Both values are nevertheless close to being statistically not significant because of the high estimated standard error 
Table IV. Expected contributions (\%) of the 10 ancestors (all males) contributing the most in all the population (animals with both parents known; $n=14306$ ) based on pedigree information.

\begin{tabular}{|c|c|c|c|c|c|c|c|}
\hline & & \multirow[b]{2}{*}{ Birth } & \multicolumn{5}{|c|}{ Reference population } \\
\hline & & & $\begin{array}{c}\text { All the } \\
\text { population }\end{array}$ & $\begin{array}{c}\text { Females born } \\
\text { from } 1998 \\
\text { to } 2002\end{array}$ & $\begin{array}{l}\text { Males born } \\
\text { from } 1998 \\
\text { to } 2002\end{array}$ & $\begin{array}{c}\text { Males } \\
\text { born } \\
\text { in } 2002\end{array}$ & $\begin{array}{c}\text { Males } \\
\text { ARR/ARR } \\
\text { born in } 2002\end{array}$ \\
\hline Rank & Animal & year & & & & & \\
\hline 1 & LCN00158 & 1991 & 5.2 & 5.6 & 5.0 & 1.0 & 0 \\
\hline 2 & LCN26110 & 1994 & 4.2 & 5.9 & 11.7 & 12.0 & 10.6 \\
\hline 3 & LCN25975 & 1994 & 4.1 & 5.9 & 9.3 & 7.2 & 0 \\
\hline 4 & LCN00159 & 1991 & 3.4 & 3.6 & 3.2 & 3.0 & 0 \\
\hline 5 & LCN09806 & 1987 & 2.5 & 2.6 & 2.2 & 1.7 & 0 \\
\hline 6 & LCN13864 & 1989 & 1.9 & 0.8 & 0.9 & 0.6 & 0 \\
\hline 7 & LCN24622 & 1993 & 1.6 & 2.4 & 2.6 & 0 & 0 \\
\hline 8 & LCN29367 & 1995 & 1.6 & 1.7 & 2.8 & 5.2 & 0 \\
\hline 9 & LCN00161 & 1994 & 1.5 & 2.4 & 2.7 & 2.1 & 0 \\
\hline 10 & LCNOO140 & 1994 & 1.4 & 1.8 & 1.0 & 0.5 & 0 \\
\hline$\Sigma$ & & & 27.4 & 32.7 & 41.4 & 33.3 & 10.6 \\
\hline
\end{tabular}

Table V. Parameters characterising the genetic variability based on genetic polymorphism information (standard errors 1000 replicates bootstrap) (weighted by Polymorphic informative content).

\begin{tabular}{|c|c|c|}
\hline & $\begin{array}{l}\text { Males born in } \\
2002\end{array}$ & $\begin{array}{c}\text { Males } \\
A R R / A R R \\
\text { born in } 2002\end{array}$ \\
\hline Mean average molecular coancestry & $0.257(0.005)$ & $0.296(0.015)$ \\
\hline \multicolumn{3}{|l|}{ Kinship distance $\left(\mathrm{D}_{k}\right)$} \\
\hline within population & $0.371(0.006)$ & $0.331(0.022)$ \\
\hline between populations & \multicolumn{2}{|c|}{$0.383(0.009)$} \\
\hline \multicolumn{3}{|l|}{ Wright F-statistics } \\
\hline heterozygote deficiency within populations ( $\mathrm{F}_{\mathrm{IS}}$ ) & $-0.002(0.014)$ & $-0.060(0.052)$ \\
\hline heterozygote deficiency between populations $\left(\mathrm{F}_{\mathrm{ST}}\right)$ & \multicolumn{2}{|c|}{$0.009(0.002)$} \\
\hline
\end{tabular}

in the population of $A R R / A R R$ males. With respect to the estimated heterozygote deficiency within populations $\left(F_{I S}\right)$, no statistical difference is detected when ARR/ARR males are selected as reproductive contributors. The values estimated are close to zero indicating that no appreciable inbreeding is present in the populations.

When regarding the number of alleles lost by selection of males according to their $\operatorname{Pr} P$ genotype, the loss of genetic variability seems more accentuated 
Table VI. Loss of genetic polymorphism in the population of $A R R / A R R$ males born in 2002 with respect to the population of all males born in 2002 .

\begin{tabular}{cccc}
\hline Marker & $\begin{array}{c}\text { No. of lost } \\
\text { alleles }\end{array}$ & $\begin{array}{c}\text { Frequency of alleles lost in the } \\
\text { population of all the males born in 2002 }\end{array}$ \\
\hline CSRD0247 & 4 & 40.0 & 0.047 \\
D5S2 & 1 & 16.7 & 0.010 \\
INRA0023 & 3 & 23.1 & 0.052 \\
INRA0049 & 2 & 20.0 & 0.047 \\
INRA0063 & 4 & 44.4 & 0.037 \\
MAF0065 & 1 & 16.7 & 0.031 \\
MAF0214 & 1 & 25.0 & 0.010 \\
MCM0042 & 4 & 50.0 & 0.115 \\
MCM0527 & 3 & 37.5 & 0.015 \\
OARAE0119 & 4 & 57.1 & 0.119 \\
OARAE0129 & 0 & 0.0 & - \\
OARCP0049 & 6 & 50.0 & 0.146 \\
OARFCB0020 & 2 & 20.0 & 0.057 \\
OARFCB0304 & 1 & 14.3 & 0.026 \\
OLADRB2 & 0 & 0.0 & - \\
\hline Average & 2.4 & 29.5 & - \\
\hline
\end{tabular}

(Tab. VI). On average, for the 15 microsatellites analysed, close to 30 percent of the alleles present in the population of males born in 2002 were lost when only $A R R / A R R$ males were selected. These lost alleles corresponded, as expected, to alleles present at low frequency in the population.

\subsection{Evaluation of a mild selection regime}

The evaluation of the use of $A R R / x x x$ rams revealed that the decision of which males should be used is not obvious. The three males selected among all the $A R R / x x x$ available, under the restrictions of minimum average coancestry coefficient within $A R R / x x x$ and $A R R / A R R$ males and the use of a maximum of 20 percent of $A R R / x x x$ rams, were different when pedigree or genetic polymorphism information were used.

When the three males were selected based on pedigree information, genealogical average coefficient of relationship with $A R R / A R R$ rams was 1.6 percent and the corresponding mean average molecular coancestry estimated 
with genetic polymorphisms was 0.278 . When they were selected based on genetic polymorphism information, the genealogical average coefficient of relationship was 3.4 percent and the corresponding mean average molecular coancestry estimated with genetic polymorphisms was 0.198 .

These results were the consequence of the different ranking of the 37 males $A R R / x x x$ according to their average relationship estimated using pedigree or genetic polymorphism information. The Spearman coefficient of correlation (0.14) was non-significantly different to zero $(p=0.39)$. This result was confirmed when males with some lack of molecular (some not amplified microsatellite), or pedigree information (some unknown grandparent) were excluded.

\section{DISCUSSION}

The genetic variability results obtained from pedigree information are not easily comparable among populations because, as pointed out by Huby et al. [19], populations are usually different in total size, collective organisation for selection or conservation, development of artificial insemination, paternity control, etc. In any case, some results are available for comparison from the few studies focussing on sheep that have been carried out to analyse the genetic variability based on pedigree information [15, 18, 19, 23, 26]. Following these results, it would be possible to state, for example, that for the reference population of females born in the last years, the effective number of ancestors and the number of ancestors explaining the 50 percent of genetic contributions is comparable to that estimated in other breeds such as Limousin [19] or Swiss Black-Brown Mountain Sheep [18]. Nevertheless, the depth of the genealogy and the pedigree completeness level vary among populations, making a correct comparison very difficult because pedigree parameters are very sensible to the completeness pedigree level and there is no way to standardise the variation of this completeness among populations.

The comparison is also difficult when using genetic polymorphism information. The importance of conservation of genetic diversity in livestock and the difficulty to assess the within and between populations genetic variability has led to consider many different genetic polymorphism based measures of genetic diversity [12]. Additionally, most of the studies published that use marker information to estimate genetic variability are focussed in the variability among breeds, populations or flocks, but few of them within breed [2,21]. In any case, it would be possible to make some comparisons indicating, for example, that the Kinship distance estimated in a previous study [1] in 
the Latxa Black Faced (0.354) is similar to the values here reported for the population of males born in 2002. Moreover, it would be possible to state that the average molecular coancestry within males ARR/ARR born in 2002 reveals a non dangerous loss of genetic variability, as it is similar to values estimated in other Spanish breeds such as Castellana [1]. Nevertheless, the molecular markers used to compute the different measures of genetic variability are not standardised, and hence the number of polymorphisms, the polymorphisms themselves and the number of alleles amplified vary among studies. Consequently, the degree of likelihood of estimates obtained from the molecular markers is different and the possible comparisons are little informative.

All these facts make the comparison of the results obtained in this work with those previously published from other sheep populations difficult. Consequently, the evaluation of the results, the diagnosis of the situation and the decision making, whatever the type of information employed, should be based exclusively on our own study results.

The results obtained in this study from pedigree information show a relevant loss of genetic variability within the population of males caused by selection of $A R R / A R R$ genotypes. Despite this result, the breed genetic variability should not be seriously affected by scrapie selection, because of the large number of females in the population (Tab. I) and the absence of selection for ARR alleles in females.

Ancestors of males $A R R / A R R$ are in general seldom represented in the whole population, and the selection of these males could result in a loss of selection pressure for other traits such as milk production. This is rather dependent on the strategy used [31]. A possible strategy is to suddenly use a big number of, and perhaps only, $A R R / A R R$ rams, with the aim of quickly increasing the $A R R$ allele frequency in the population. These rams would have to be found anywhere, regardless of their estimated breeding value. Therefore, this would greatly decrease the selection pressure for milk production. The other possible strategy is a smooth increase in the frequency of the $A R R$ allele, which can be achieved through a slight decrease in the selection intensity, increasing the number of rams. For example, let the number of chosen lambs (future rams) increase by 10 percent, based on their estimated breeding value for milk production. Among these, all rams with an $A R R$ allele would be retained and in some generations a very high $A R R$ frequency would be achieved. In this sense, studies done according to the population structure of this breed show that if the selection pressure is reduced from 5 to 10 percent the genetic gain is reduced around 10 percent. 
On the contrary, the reduction in the number of ancestors contributing to the male population (Tab. III) is mitigated by the absence of selection in females, where all the ancestors are represented. Furthermore, the number of Latxa Black Faced-type Navarra animals involved in the breeding programme could represent around 20 percent of the population, and consequently, an important amount of the genetic variability of the breed will not be affected by selection pressure on scrapie susceptibility or dairy performances.

Nevertheless, as indicated when presenting the results, the pedigree completeness level is small and results obtained from pedigree analysis could be insufficient and they should be carefully interpreted. Despite this precaution, the results obtained from genetic polymorphism in terms of reduction of variability between males are similar and both sources of information agree. Genetic polymorphisms showed that although the genetic variability loss could be acceptable in terms of conservation of the population, inevitable erosion of rare alleles would be produced. However, the indicated absence of selection in females and the large population that is not involved in official milk recording implies that the increase of average coancestry and the loss of rare alleles will be mitigated at the whole breed population level.

Finally, in order to reduce the loss of genetic variation, one possibility to consider is the use of $A R R / x x x$ males to be mated with carrier females of the $A R R$ allele. This also makes the use of $A R R / x x x$ males with high genetic value for milk production possible. However, the election of males to be used in order to minimise the average coancestry is, in this study, dependent on the source of information used, pedigree or genetic polymorphisms. It is difficult to state which one of them should be used when there is an important lack of pedigree information or a small number of microsatellites is used, like in this study. The information provided by a small number of genetic polymorphisms can be useful to estimate the effect of selection on genetic variability when the amount of pedigree information is small, but insufficient to correctly establish the genetic relationships among animals, and therefore is also insufficient to take decisions about mild selection regimes against scrapie susceptibility based on the use of heterozygous $A R R$ carrier males.

In summary, all the results suggest that no great negative effect on genetic variability is expected in the short time in Latxa Black Faced-type Navarra by selection of males against scrapie susceptibility, especially because the selection favouring $A R R$ is not applied to the female population. However, a loss of founder animals and low frequency alleles will occur in the selected $A R R / A R R$ population of males. 


\section{ACKNOWLEDGEMENTS}

The authors wish to thank CONFELAC for providing the data, specially the breeders' association ASLANA for providing the blood samples, F. Rendo and A. Estonba for laboratorial assistance, and J.P. Gutiérrez for helpful comments. Financial support for this work was provided by the Spanish "Ministerio de Ciencia y Tecnología" (EET2001-4891-C03-3).

\section{REFERENCES}

[1] Alvarez I., Gutierrez J.P., Royo L.J., Fernandez I., Gomez E., Arranz J.J., Goyache F., Testing the usefulness of the molecular coancestry information to assess genetic relationships in livestock using a set of Spanish sheep breeds, J. Anim. Sci. 83 (2005) 737-744.

[2] Arora R., Bhatia S., Genetic structure of Muzzafarnagri sheep based on microsatellite analysis, Small Ruminant Res. 54 (2004) 227-230.

[3] Arranz J.J., Bayon Y., San Primitivo F., Genetic variation at microsatellite loci in Spanish sheep, Small Ruminant Res. 39 (2001) 3-10.

[4] Boichard D., PEDIG: a fortran package for pedigree analysis suited for large populations, in: Proceedings of the 7th World Congress on Genetics Applied to Livestock Production, 19-23 August 2002, Inra, Castanet-Tolosan, CD-Rom, communication 28-13.

[5] Boichard D., Maignel L., Verrier E., The value of using probabilities of gene origin to measure genetic variability in a population, Genet. Sel. Evol. 29 (1997) $5-23$.

[6] Bowles D., Gilmartin P., Holt W., Leese H., Mylne J., Pincton H., Robinson J., Simm G., Evolution of Heritage GeneBank into The Sheep Trust: conservation of native traditional sheep breeds that are commercially farmed, environmentally adapted and contribute to the economy of rural communities, in: Simm G., Villanueva B., Sinclair K.D., Townsend S. (Eds.), Farm animal genetic resources, Nottingham University Press, Nottingham, 2004, pp. 45-55.

[7] Buschmann A., Lühken G., Schultz J., Erhardt G., Groschup M.H., Neuronal accumulation of abnormal prion protein in sheep carrying a scrapie-resistant genotype (PrPARR/ARR), J. Gen. Virol. 85 (2004) 2727-2733.

[8] Caballero A., Toro M.A., Analysis of genetic diversity for the management of conserved subdivided populations, Conserv. Gen. 3 (2002) 289-299.

[9] Detwiler L.A., Baylis M., The epidemiology of scrapie, Rev. Sci. Tech. O.I.E. 22 (2003) 121-143.

[10] Diez-Tascon C., Littlejohn R.P., Almeida P.A.R., Crawford A.M., Genetic variation within the Merino sheep breed: analysis of closely related populations using microsatellites, Anim. Genet. 31 (2000) 243-251.

[11] EC, Commission decision (2003/100/EC) of 13 February 2003 laying down minimum requirements for the establishment of breeding programmes for resistance to transmissible spongiform encephalopathies in sheep, Official Journal of the European Union, 14.2.2003, L41/41. 
[12] Eding H., Meuwissen T.H.E., Marker-based estimates of between and within population kinships for the conservation of genetic diversity, J. Anim. Breed. Genet. 118 (2001) 141-159.

[13] FAO, Guidelines for development of national farm animal genetic resources management plans. Measurement of domestic animal diversity (MoDAD): recommended microsatellite markers, http://dad.fao.org/en/refer/library/guidelin/ marker.pdf, 2004.

[14] Gabiña D., Arrese F., Arranz J., Beltran de Heredia I., Average milk yields and environmental effects on Latxa sheep, J. Dairy Sci. 76 (1993) 1191-1198.

[15] Goyache F., Gutierrez J.P., Fernandez I., Gomez E., Alvarez I., Diez J., Royo L.J., Using pedigree information to monitor genetic variability of endangered populations: the Xalda sheep breed of Asturias as an example, J. Anim. Breed. Genet. 120 (2003) 95-105.

[16] Gutiérrez J.P., Goyache F., A note on ENDOG: a computer program for analysing pedigree information, J. Anim. Breed. Genet. 122 (2005) 172-176.

[17] Gutiérrez J.P., Royo L.J., Alvarez I., Goyache F., MolKin v2.0: a computer program for genetic analysis of populations using molecular coancestry information, J. Hered. 96 (2005) 718-721.

[18] Hagger C., Genetic variability of two Swiss sheep breeds derived from pedigree information, in: Proceedings of the 7th World Congress on Genetics Applied to Livestock Production, 19-23 August 2002, Inra, Castanet-Tolosan, CD-Rom, communication 26-21.

[19] Huby M., Griffon L., Moureaux S., De Rochambeau H., Danchin-Burge C., Verrier E., Genetic variability of six French meat sheep breeds in relation to their genetic management, Genet. Sel. Evol. 35 (2003) 637-655.

[20] ISAG, DNA panels for sheep and goats 2003: markers, procedures and allele frequencies, http://www.isag.org.uk/ISAG/all/markers_sheep_goats.doc, 2003.

[21] Ivankovic A., Dovc P., Kavar T., Caput P., Mioc B., Pavic V., Stuhec V., Leto J., Genetic characterisation of the Pag island sheep breed based on microsatellite and mtDNA data, Small Ruminant Res. 57 (2005) 167-174.

[22] Legarra A., Ugarte E., Beltrán de Heredia I., Análisis de asociación entre genotipos de PrP y producción de leche en la raza Latxa. ITEA Producción animal, 100A (2004) 127-133.

[23] Maiwashe A.N., Blackburn H.D., Genetic diversity in and conservation strategy considerations for Navajo Churro sheep, J. Anim. Sci. 82 (2004) 2900-2905.

[24] MAPYA, Report on the study of the genotypes of the prion protein in Spain. Ministerio de Agricultura, Pesca y Alimentación, Madrid, Spain, 2003.

[25] Orge L., Galo A., Machado C., Lima C., Ochoa C., Silva J., Ramos M., Simas J.P., Identification of putative atypical scrapie in sheep in Portugal, J. Gen. Virol. 85 (2004) 3487-3491.

[26] Palhière I., Barillet F., Astruc J.M., Aguerre X., Belloc J.P., Briois M., Fregeat G., Bibé B., Rochambeau H., Boichard D., Analysis of the genetic variability of the Basco-Bearnaise, Lacaune and Manech dairy sheep breeds using genealogical data, Rencontres Rech. Ruminants 7 (2000) 153-156. 
[27] Pariset L., Savarese M.C., Cappuccio I., Valentini A., Use of microsatellites for genetic variation and inbreeding analysis in Sarda sheep flocks of central Italy, J. Anim. Breed. Genet. 120 (2003) 425-432.

[28] Rendo F., Iriondo M., Estonba A., Un panel de 17 loci microsatélites para el control genealógico y la trazabilidad en ganado ovino, in: Proceedings of the IV Congreso de la Sociedad Española de Genética, 8-10 September 2003, Escorial, P88.

[29] Rendo F., Iriondo M., Jugo B.M., Mazón L.I., Aguirre A., Vicario A., Estonba A., Tracking diversity and differentiation in six sheep breeds from the North Iberian Peninsula through DNA variation, Small Ruminant Res. 52 (2004) 195202.

[30] Rochambeau H. de, Fournet-Hanocq F., Khang V.T.J., Measuring and managing genetic variability in small populations, Ann. Zootech. 49 (2000) 77-93.

[31] Smulders J.P., Serrano M., Pérez-Guzmán M.D., Jiménez M.A., Jurado J.J., Consecuencias genéticas de los planes de erradicación de la E.E.T. en el esquema de selección de la raza ovina Manchega, Información Técnico-Económica Agraria Vol. Extra 26 (2005) 138-140.

[32] Stahlberger-Saitbekova N., Schlapfer J., Dolf G., Gaillard C., Genetic relationships in Swiss sheep breeds based on microsatellite analysis, J. Anim. Breed. Genet. 118 (2001) 379-387.

[33] Steffen P., Eggen A., Dietz A.B., Womack J.E., Stranzinger G., Fries R., Isolation and mapping of polymorphic microsatellites in cattle, Anim. Genet. 24 (1993) 121-124.

[34] Toro M.A., Barragán C., Óvilo C., Estimation of genetic variability of the founder population in a conservation scheme using microsatellites, Anim. Genet. 34 (2003) 226-228.

[35] Ugarte E., Arrese F., Legarra A., Organisational changes in the Latxa breeding programme to introduce selection for milk quality, in: Gabiña D., Sanna S. (Eds.), Breeding programmes for improving the quality and safety of products. New traits, tools, rules and organization?, Options Méditerranéennes, Série A, Séminaires Méditerranéens, 55, CIHEAM-IAMZ, Zaragoza, 2003, pp. 141-146.

To access this journal online: www.edpsciences.org 